\title{
Student perspectives of and experience with sense-making: a case study
}

\author{
MacKenzie Lenz, ${ }^{1}$ Kelby T. Hahn, ${ }^{1}$ Paul J. Emigh, ${ }^{1}$ and Elizabeth Gire ${ }^{1}$ \\ ${ }^{1}$ Department of Physics, Oregon State University, Corvallis, OR 97331
}

\begin{abstract}
One difference between expert and novice problem-solvers is their use of sense-making strategies. Sense-making while solving physics problems involves coordinating the use of algebraic symbols with conceptual understandings, understandings of geometric relationships, and intuitions about the physical world. We have developed a new sophomore-level course that explicitly supports students in using various sense-making strategies in the context of classical mechanics and special relativity. In this paper, we examine one student whose sense-making performance improved dramatically throughout the course. We present an analysis of a series of interviews with this student, his homework, and his pre- and post- sense-making assessments. While he reports having been familiar with many of the sense-making strategies emphasized in the course, he discusses several ways his use of these strategies was enriched. We see evidence of this shift in his written coursework.
\end{abstract}

\section{INTRODUCTION}

Expert physicists use many different sense-making strategies when solving physics problems [1]. We define sense-making while solving physics problems to be the process by which one coordinates the use of algebraic symbols with conceptual understandings, knowledge of geometric relationships, and intuition about the physical world. A typical goal of physics instruction is to encourage and instruct students to develop sense-making skills and habits [2]. However, sense-making strategies are often only part of the "hidden curriculum" [3] and not explicitly taught. Many instructors demonstrate and expect students to do sense-making, but explicit instruction on sense-making strategies is uncommon [4].

Some studies have examined students' epistemic beliefs about physics $[5,6]$, but few studies explicitly look at student beliefs about sense-making in physics. The Colorado Learning Attitudes about Science Survey (CLASS) [7] has a sense-making cluster that contains 7 of the 42 survey items. No items on the CLASS directly assess student views about the usefulness of sense-making strategies or the need for learning sense-making strategies. We have found no studies that have examined how explicit instruction of sense-making strategies impacts students' views about sense-making.

In this paper, we discuss one student's experience in a course that emphasizes physics sense-making. We report on his beliefs about sense-making and explore how his sense-making practices changed during the course.

\section{INSTRUCTIONAL CONTEXT}

The instructional context of this study is a newly designed course - Techniques of Theoretical Mechanics that has an explicit sense-making learning goal. It is 10 weeks long and meets for 50 minutes 3 times per week. The physics content of the course includes classical mechanics (Newtonian, Lagrangian, and Hamiltonian techniques) during the first 7 weeks and special relativity in the last 3 weeks. In Spring 2017, author EG was the instructor and 27 students completed the course. Students may take it concurrently with the last term of introduc- tory physics (although transfer students are scheduled to take it at the end of their junior year).

Physics sense-making is the theme of the course. The sense-making goal was treated on equal footing with the physics content goals: it appeared on the syllabus, was explicitly discussed in almost every class meeting, appeared in every homework problem, and was included on exams. Every homework problem included prompts to do sense-making. Early in the course, these sensemaking strategies were prescribed by name. Later in the course, students were prompted to do sense-making, but the specific strategies were not prescribed. During smallgroup problem-solving activities in class (at least once per week), the instructor asked for several volunteers to come to the board to demonstrate a sense-making strategy they used for the problem. During the second week of class, while considering a Newtonian mechanics problem, the class brainstormed a list of sense-making strategies (Table I) which was posted on the course website for reference.

TABLE I. Student-generated list of sense-making strategies.

\begin{tabular}{ll}
\hline \hline - Dimensional Checking & - Compare to what you know \\
- Direction/Sign of Answer & - Plug answer back into start \\
- Reasonableness of Answer & - Assumptions/ Idealizations \\
- Limiting/Special Cases & - Proportionality \\
- Graphical Analysis & \\
\hline \hline
\end{tabular}

\section{METHODS}

As part of a larger study about how to support students' development of sense-making skills and habits, we interviewed 4 students about every 2-3 weeks and once after the final exam. During these interviews, we asked about their experiences in Theoretical Mechanics. The students we interviewed were purposefully chosen to represent high, medium, and low performing groups on an assessment of sense-making skills given on the first day of class. Originally 3 students were chosen, one from each category, but a forth student was added after an original participant could not continue in the study. The assessment included multiple choice items about checking units/dimensions (2 items), special cases (3 items), 
appropriate functional behavior (1 item), and reasonable magnitudes of quantities ( 1 item). A low score was between 0-2 correct answers, medium was 3-5, and high was 6-7 for the purpose of choosing participants.

In this paper, we focus on 1 student, Shane, because we found him to be an extreme case in terms of change in sense-making performance. An extreme case represents a large variation in the dimension of interest, in this case, sense-making performance [8]. Shane scored very low on the multiple-choice portion of the sense-making pretest (1/7 correct while the class average was $3 / 7$ with standard deviation of 1.8). However, he ended up with the fifth highest grade out of 27 students in a class where assignments routinely asked for demonstrations of sensemaking. We calculated a relative improvement factor (RIF), defined as the \# of SD from the mean course score minus the \# of SD from the mean pre-test score. Shane had the highest relative improvement $(\mathrm{RIF}=1.88)$ out of all the students that took the pre-test, furthering our categorization of him as an extreme case.

Studies of extreme cases are useful for exploring possible causes or effects. In this case, we are interested in understanding how this course affected Shane's views about sense-making and his sense-making skills and habits. As Shane represents an extreme case, we are careful to not make generalized claims from this data. Instead, we attempt to identify explanations for this case that can be investigated further in a larger study.

TABLE II. 6 questions repeatedly asked in all 5 interviews.

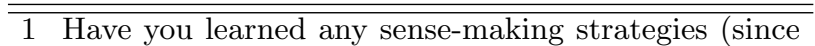
we talked last)?

2 What sense-making strategies have you been using (since we talked last)? with or with out prompting?

3 Do you find these sense-making strategies useful? Why or why not?

4 Are there any ways that sense-making strategies have helped you in this course?

5 Are you having difficulties with any sense-making strategies?

6 Has anything interesting happened since we last meet that you think is relevant to these conversations?

Shane participated in 5 interviews. Each interview was audio and video recorded and full transcriptions were made. The transcripts were read multiple times by 1 researcher to identify pertinent episodes. To mitigate bias another researcher read the transcripts and independently identified themes. The themes identified by the 2 researchers were found to be consistent, therefore consensus was achieved. In order to retain meaning, all quotes from the transcripts were given contextual memos.

We examined a subset of Shane's written coursework to triangulate his statements about his sense-making practices. We examined 5 homework assignments, where strategies were not prescribed for the students, and the aforementioned sense-making assessment that was given as a pre- and post-test. Additionally, we looked at Shane's end-of-course feedback survey for statements about his beliefs and practices around sense-making. A limitation of this study is that we have little evidence to corroborate Shane's reports about his behaviors and past events. However, his reports of these events are valuable in that they reflect his attitudes about various aspects of sense-making.

\section{RESULTS}

\section{A. Shane believes his knowledge of sense-making strategies was refined but not expanded.}

Shane reported that he did not learn new sense-making strategies in the Theoretical Mechanics course. In the 2 introductory physics courses that Shane took before this course, he was required to provide a written reflection on his solutions for hand-in homework and on some exams.

All the sense-making strategies that we've gone over in class were things we covered in the general series, so I wouldn't say I've learned anything new or if there was anything really outstanding for me. (Interview 1)

Shane reported that he used sense-making strategies he had used in the introductory physics. When asked the second repeated question (Table II), "What sensemaking strategies have you been using since we talked last?", in all 5 interviewers, Shane said that he was using dimensional checking and special/limiting case analysis. On a few occasions, he mentioned proportional reasoning (coded as functional dependence). This is consistent with our assessment of a subset of his homework solutions. On Homework 4-8 we coded 43 instances of sense-making in response to explicit, open-ended sense-making prompts. The most common sense-making strategies Shane used were checking dimensions (14 instances), checking special/limiting cases (11 instances), examining functional dependence (5 instances), checking the sign of the answer (4 instances), and making a connection to physics concepts ( 4 instances). When asked why he tended to use dimensional analysis, checking special cases, and proportional reasoning, he said it was "because those 3 are really short and easy" (Interview 4).

Shane said that he changed how he performed checking units/dimensions. He attributed the change to a discussion in class.

Interviewer: When you're asked to check dimen-

sions, what does that mean to you?

Shane: If you asked me that last year, I would have said units, like in meters and second, but that's kind of become length, time, I mean those are the biggies for us.

Interviewer: When did that change happen?

Shane: I think the first day of this class.

(Interview 2)

We also saw evidence of how explicit instruction changed the way Shane used or when Shane used certain strategies. This is evident in Shane's understanding of when or how to use specific sense-making strategies as his knowledge was broadened to include new physics topics. For example, after learning about special relativity, he said: 
I've learned, kind of, new ways to apply the [sensemaking strategies] I already knew. So for special relativity just applying what I already know, ya know. If I do a Lorentz transformation to some kind of coordinate I can think about each component and just think, step back and think about length contraction and time dilation and it makes sense...graphing and geometric arguments have become much more pertinent these past few weeks. With spacetime diagrams...like, submitting what I think would happen in terms of length contraction or time dilation. And then I could check that with a spacetime diagram. (Interview 5)

Outside of the interview data, we analyzed Shane's pre- and post- sense-making assessments. In looking at what strategies he used, we saw that on 1 item that he got wrong on the pre-test but correct on the post-test, he altered his strategy from checking units on the pretest to checking dimensions on the post-test. We also found that on 2 other items that he got wrong on the pre-test but correct on the post-test, he had changed strategies from the pre-test to the post-test. These data support Shane's description of changing how he performed unit/dimension checking and that his application of sense-making strategies was refined during the course.

\section{B. Sense-making strategies became formal for Shane.}

Although Shane was familiar with sense-making strategies from introductory physics, Shane indicated that these strategies had become more concrete for him in the Theoretical Mechanics course. Shane described having a list of sense-making strategies as being valuable (Table I). He also expressed a belief in the importance of holding students accountable for their understanding of sense-making strategies on course assignments.

Interviewer: So you did reflection in that [introductory physics] for the written homework. The required at the end reflection stuff.

Shane: Oh well that really doesn't compare to this [Theoretical Mechanics] class at all because you can literally just say 'the dimensions make sense and the answer is reasonable' and then say what the answer means, and not actually understand anything you just said but get full credit. It, like those, that wasn't an environment to really learn sense-making skills.

Interviewer: The skills that you used there and the skills that you know now. Did you just learn a whole wealth of new ones or do you feel like you just made those ones better?

Shane: It was kind of like I knew about all those skills [sense-making strategies] before but they had never been confirmed to me or shown to me so they were all kind of nebulous. And because I was never, they were never talked about in the general physics series I didn't really exercise the more complicated sense-making strategies. But this class actually creating a list of sense-making strategies brought them together. (Interview 5)

In that statement, Shane indicated that, although he was aware of various sense-making strategies in introductory physics, he did not believe that he used the "more complicated" sense-making strategies in those courses. It is unclear from this statement whether Shane believes that explicit discussion of sense-making strategies was what encouraged him to use some strategies more often.

However, we do see evidence that Shane may have felt constrained to use only sanctioned sense-making strategies on course assignments. In Interview 3, when asked if he has learned any new sense-making strategies (first repeated question, Table II):

I didn't know that solving the question 2 different ways was an official sense-making strategy for this class... I think we used that last class, or 2 classes ago she mentioned it. So I thought 'oh, well I've wanted to do that on the homework but I haven't' so I'll do it now probably. (Interview 3)

When we asked Shane if he thought the reflection section of the introductory physics homework rubric should continue to be required, Shane said:

Of course it should be required. And they should honestly require more. It shouldn't be such a huge leap from general physics, at least from 213 [3rd term of Introductory Physics] to this class. There shouldn't be such a leap in sense-making strategies. And I think [the introductory physics instructor] actually does a good job talking about them during lecture but it feels like the homework rubric in that class is outdated. (Interview 5)

This statement indicates that at the end of the Theoretical Mechanics course, Shane believed that only demonstrating sense-making without holding students accountable is insufficient support for students to learn how to do sense-making.

Shane also described the Challenges course, another new sophomore course that is required of physics majors, as including little to no emphasis on sense-making. Shane stated:

I feel like in modern physics [Challenges], in the class that he (the instructor) taught, we were actually dealing with really complicated subjects but using really simple models so we didn't actually, like as a class, know enough about, like know enough beyond the really simple model of the subject to apply sense-making. (Interview 5)

This statement seems to indicate a belief that sensemaking requires some minimum threshold of understanding before it can be done. The interviewer knew that Fermi estimation was emphasized in the Challenges course and asked Shane if he considered it a sense-making strategy; he did not. He stated that Fermi estimation was "just doing it [the calculation] again but worse. I don't know, I would say no." (Interview 5) We consider 
Fermi estimation to be an important sense-making strategy, as does the instructor of the Challenges course. Despite this, that instructor did not label Fermi estimation a sense-making strategy and it was not discussed in the Theoretical Mechanics course. This example further supports the notion that identifying sense-making strategies may be important for students. Students may not view a strategy as a productive way of making sense of a physical situation if the strategy is not explicitly called out as a sense-making strategy.

\section{Shane reports that he routinely does unprompted sense-making.}

One aspect of this new course was to encourage students to use sense-making processes throughout a problem. Shane reported multiple times that he used sensemaking in the middle of problems as well as at the end. His first statement about doing this happens in the first interview when he says "I'm naturally using a few strategies as I'm doing the question. So I'm applying that analysis [dimensional analysis] to intermediate steps as well." (Interview 1) The interviewer asked for an example of this spontaneous sense-making and Shane expressed that "you can just look at 1 of your intermediate steps and just spend half a second looking at the dimensions." This statement indicated that Shane views simple sensemaking processes as being useful at all points in problem solving process.

We asked Shane about unprompted sense-making again in Interview 2. Shane said, "Well I definitely do unprompted sense-making on the homework where like halfway through my solution I'll actually use a different color... so I'll circle the arguments of some kind of logarithmic function or exponential and I'll just check that its unit, dimensionless, like in the middle of the question."

$$
\begin{gathered}
\frac{k}{b} \ln \left(\frac{b}{k} v-v_{\text {ex }}\right)-\frac{k}{b} \ln \left(-v_{\text {ex }}\right)=\ln (m)-\ln \left(m_{0}\right) \\
\frac{k}{b} \ln \left(\frac{\frac{b}{k} v-v_{e x}}{-v_{\text {ex }}}\right)=\ln \left(\frac{m}{m_{0}}\right)
\end{gathered}
$$

FIG. 1. Unprompted unit checking on homework 4.

We looked for evidence of umprompted sense-making in Shane's solutions to Homework 4-8. We found 2 clear instances of unprompted sense-making, 1 in Homework 4 and another in Homework 5. Fig. 1 shows Shane changing pen colors when doing unprompted sense-making as he stated in Interview 2.

Shane described 3 contexts outside of the Theoretical Mechanics course where he used, or tried to use, the sense-making strategies featured in the course. First, Shane was a learning assistant in the calculus-based introductory physics sequence, and he described using sense-making strategies when helping those students and when tutoring students in his dorm. Second, he tried to use sense-making strategies in the 2 math courses (Linear Algebra and Sequences $\&$ Series) he was taking concurrently with Mechanics. He said it was difficult to use the physics sense-making strategies in those courses because the problems do not have a physical context. Third, he was auditing an advanced physics course, Introduction to Solid State, and was having mixed success in using dimensional analysis in that context.

I'm auditing solid state, Introduction to Solid State. I've had trouble using sense-making strategies in that class because we use so many operators where it's like the dimensions, I'm like always uncertain about the dimensions basically. But another good thing is that we, so many of the functions in that class, like so many of the wave functions, have like e to the some power and ... there's so many terms in those powers where you can do a lot of dimensional checking to make sure the powers are dimensionless. (Interview 3)

\section{DISCUSSION}

This case study has helped us to understand the ways in which Shane has changed as a physics sensemaker. Even though Shane was familiar with sensemaking strategies from introductory physics, Shane benefited from focused practice with these strategies. Shane said that the course made sense-making strategies more formal for him and refined how he performed at least some of the strategies. This formality gave Shane permission to use certain strategies that he did not inherently consider valid before this instruction. We also saw evidence about how explicit instruction changed the way Shane used or when Shane used certain strategies.

Shane reported using these strategies often in situations where he was not prompted to do so and in situations outside of the Theoretical Mechanics course. This extra practice likely contributed to his increased proficiency with these strategies. We are interested in further exploring factors that contribute to students using sensemaking strategies across contexts.
[1] C. Singh, Am. J. Phys. 70 (2002).

[2] A. R. Warren, Phys. Rev. ST Phys. Educ. Res. 6, 020103 (2010).

[3] E. F. Redish, Teaching Physics: With the Physics Suite (John Wiley \& Sons, Hoboken, NJ, 2003).

[4] M. Lenz and E. Gire, in PERC Proceedings (2016).
[5] D. Hammer, Phys. Teach. 27, 664 (1989).

[6] C. Stathopoulou and S. Vosniadou, 32, 255281 (2007).

[7] W. Adams, K. Perkins, N. S. Podolefsky, M. Dubson, N. Finkelstein, and C. Wieman, Phys. Rev. ST Phys. Educ. Res. 2 (2006).

[8] J. Seawright and J. Gerring, Political Research Quarterly 61, 294 (2008). 